\title{
Interactions between refugee and local preschool children and prejudice or discriminatory behaviors: Teachers' observations
}

\author{
Servet Kardeş ${ }^{1}$ and İshak Kozikoğlu ${ }^{2}$ \\ ${ }^{1}$ Van Yüzüncü Yal University, Faculty of Education, Turkey (ORCID: 0000-0002-4230-6628) \\ ${ }^{2}$ Van Yüzüncü Yıl University, Faculty of Education, Turkey (ORCID: 0000-0003-3772-4179)
}

\begin{abstract}
This study is designed to identify the prejudice or discriminatory behaviors towards refugee children that can be observed in children in early childhood and to determine the extent of the interaction of refugee children with other children. It is a case study which is one of the qualitative research methods. In this study, face-to-face interviews were conducted with 15 pre-school teachers, who had refugee children in their class, through the semi-structured interview form developed by the researchers. Descriptive analysis was used to analyze the data. As a result of the study, it was concluded that although there is no complete integration in the classes with refugee children, children do not have any prejudice or discriminatory behaviors towards refugee children, and even Turkish children cooperate with refugee children. In the education and adaptation of refugee children, it was concluded that the failure in speaking the Turkish language is an important obstacle, and the way in which children are raised in the family and cultural differences cause disciplinary problems in refugee children in some cases. It suggests that provision in the classroom of language and adaptation training for the integration of refugee children will help to integrate the cultural differences of children into the classroom environment.
\end{abstract}

Keywords: Early childhood; Preschool teachers; Refugee children; Prejudice; Discriminatory behaviors

Article History: Submitted 10 November 2020; Revised 20 January 2021; Published online 15 February 2021

\section{Introduction}

People are not born with prejudice. Prejudices are learned in social context (Bigler \& Liben, 2007; Devine, 1989). In their research, Kelly et al. (2005) found that not newborn babies but babies of three-months old preferred faces from their own ethnic group. Prejudice is an attitude towards human dignity and a perception that harms unity among people. Prejudice is a hostile attitude based on an incorrect and inflexible generalization. It is also a judgment that ignores truth and honesty. Prejudice poisons the relationships between individuals. It can be directed to a group as a whole or to an individual just because he/she is a member of that group. A person may discriminate against others to feel stronger and raise his/her self-esteem (Allport, 1979). Prejudice can be expressed as thinking or perceiving a person as inadequate by comparing with another person or group. Prejudice arises for individuals or groups that deviating from the ideal

Address of Corresponding Author

Servet Kardeş, PhD, Van Yüzüncü Yll University, Faculty of Education, Department of Special Education, 65000, Van, Turkey.

$\nabla$ servetkardes@yyu.edu.tr

How to cite: Kardeş, S. \& Kozikoğlu, İ. (2021). Interactions between refugee and local preschool children and prejudice or discriminatory behaviors: Teachers' observations. Journal of Pedagogical Research, 5(1), 114-125. http:/ / dx.doi.org/10.33902/JPR.2021067282 
appearance and behavior of the dominant group (Carter \& Rice, 1997). Discrimination often results from prejudices. Discrimination and prejudice can take the form of verbal abuse, avoiding relationships, discrimination, racism and violence against people or their assets (Allport, 1979).

The origins of prejudice and discrimination seen in adults go back to early childhood and begin around 4-5 years old (Aboud et al., 2012; McGlothlin \& Killen, 2006; Raabe \& Beelmann, 2011). Eliminating the prejudice and discriminatory behaviors of children in early childhood is important for both the health and well-being of children (Duckitt et al., 1999). Social exclusion that occurs in early ages has negative effects on the healthy social and psychological development of children. Exposure to exclusion can create stress and anxiety, and may occur as depression, social withdrawal and adjustment problems (Killen \& Rutland, 2011; Rubin et al., 2006). Children determine their fair behaviors and unfair prejudices in line with their own moral propositions and messages of the social environment (Bigler \& Liben, 2007).

Once children begin to understand social groups and find out that they are members of a social group, they become aware of the differences between social groups. In the early childhood years, individuals tend to see children who are similar to themselves as good and those who are different from themselves as bad (Aboud \& Amato, 2001). According to the social identity theory, children regard other children who resemble them as good and children who are different from them as bad (Tajfel et al., 1979). For example, Clark and Clark (1958) in their study left a variety of white and black skinned dolls and pupets in front of the children. The children were asked to choose the puppet or doll they preferred to play with. As a result, children between the ages of 3-8 preferred white puppets and babies more and stated that they had beautiful colors. On the other hand, the children had bad connotations for the children because they were seen as looking bad. However, it was stated that this situation was not caused by prejudice and hostility in children, they only had positive attitude towards those who are similar to them, namely their own groups (Cameron et al., 2001).

Cognitive development, social context and individual differences affect children's perception of discrimination (Spears Brown \& Bigler, 2005). Children's prejudices are often influenced by their parents and peers (Aboud \& Fenwick, 1999). Children also form their exclusionary attitudes and prejudices as a result of social traditions or group norms (Killen \& Rutland, 2011; Rubin et al., 2006). For example, he/she can prevent his/her friend from participating in the game with an approach that says "he/she cannot be in our team because he/she is not fast enough and we have to win this race". Or they can go against the peer group exclusion because of moral norms such as equality and fairness. For example, they might have an approach that says, "We should also take him/her to our game, give him/her a chance to see how fast he/she is". Studies show that when children exclude someone, they often make such a decision based on the decision of group members or traditional criteria. Moral norms are not effective in this process (Rutland \& Killen, 2015).

In a rapidly changing world, teachers teach children from diverse backgrounds and different characteristics. While some of these students have an advantageous position in terms of ethnicity, gender, class, language, religion and ability, some students may be disadvantaged due to these situations (Healey et al., 2018). In order to create an integrated classroom environment aganist prejudice and discrimination, the teaching and curriculum should be based on children's needs and experiences. Teaching and curriculum should be formed to develop multicultural and multiperspective approaches (Tan, 2001). Classrooms should be a participatory and experience-based environment. Children's lives should be the starting point for fighting against discrimination and teaching to live together. Children should be able to solve problems in a decision-making and collaborative way. Children should feel safe emotionally. A classroom environment should be created where children will protect each other and develop a relationship of trust (Boutte, 2008).

Teachers should adopt a multicultural education model based on concepts of social justice in order to deal with prejudice and discriminatory behaviors that may arise in children. In a democratic society, education should help students gain the knowledge, attitudes and skills they 
will need to be part of a fair society (Banks, 1991). Discussing the differences openly, responding to the curious questions of children about differences, avoiding gender patterns, talking about the family history of children with different cultures and making them proud, giving examples from different backgrounds and different cultures will contribute to integration in the classroom (Williams \& Nguyen, 2018). Moreover, role-playing and empathy development techniques can be used to overcome prejudice and exclusionary attitudes that can be seen in children. Children should know what other people might feel in the situations of exclusion (Rutland \& Killen, 2015). Children need to be supported to meet and share with people who have different life experiences. Children's questions about people who are different should be answered quickly and simply. Children's fears or misunderstandings about differences should be corrected. We should help children adopt differences with books or other materials (Crary, 1992).

Early intervention programs can be implemented to eliminate social exclusion, prejudice and children's discriminatory behaviors (Rutland \& Killen, 2015). In this sense, school-based antidiscrimination programs should be based on respect and tolerance of differences. In order to eliminate prejudices in children, it is important to give information to children in accordance with their cognitive development about eliminating the prejudice as well as taking a positive attitude towards differences (Aboud \& Fenwick, 1999).

When the studies in the literature are examined, Araujo \& Strasser (2003) concluded that children around 3-4 years old started to establish their gender and ethnic identity. They also revealed that prejudices and patterns in the home, society and media negatively affect children's feelings about themselves and others. In other research, Bigler and Liben (1993) found that children with better cognitive development have less prejudice. It revealed that children who have gained the concept of protection and classifying objects according to more than one feature have less prejudice. Aboud et al. (2012) and McGlothlin and Killen (2006) revealed that training about living with differences has positive results for the change of attitude among children in the dominant group. In his doctoral thesis, Kardeş (2018) concluded that the social emotional intervention program is more effective in the classroom environment where Turkish and Syrian children receive education together and contributes to the social and emotional development of children.

In the literature, there are no studies which examine prejudice or discriminatory behaviors of children in early childhood in Turkey. Studies conducted (Aboud et al., 2012; Araujo \& Strasser, 2003; McGlothlin \& Killen, 2006; Powlishta et al., 1994; Raabe \& Beelmann, 2011) show that children in early childhood have prejudice and discriminatory behaviors. Determining the prejudice and discriminatory behaviors of children can help educators develop strategies to eliminate those behaviors. In addition, while it is easier to deal with prejudices in early childhood, this situation becomes more difficult in adulthood. Prejudice and discrimination can lead to polarization and violence in society. Therefore, revealing the prejudice and discriminatory behaviors in children from early ages and preventing those behaviors will contribute to the integration of the society. In addition, it is thought that this study will fill an important gap in the related literature.

The purpose of this study is to examine the prejudice and discriminatory behaviors of Turkish children who are educated in the same environment with refugee children and to determine the interaction of refugee children with their Turkish peers. The following questions are used in this study to establish the opinions of preschool teachers.

1) How do refugee children interact with other children in the classroom?

2) What are the opinions of teachers about Turkish children's prejudice or discriminatory behaviors against refugee children?

3) What are the teachers' suggestions for the education of refugee children?

This study is considered important in terms of investigating the prejudice or discriminatory behaviors of children in early childhood by obtaining the opinions of teachers, which has not been studied. In addition, it is known that there has been an important wave of immigration to our 
country due to the civil wars in recent years especially in the Middle East countries (Syria, Afghanistan, etc.) and this situation brought up the refugee problem in education. There is considerable research (Başar et al., 2018; Erdem, 2017; Güngör \& Şenel, 2018; Öztürk, 2018; Şimşir \& Dilmaç, 2018; Tosun et al., 2018) about the problems faced by refugee students in upper education levels (primary, secondary, high school, university, etc.). However the studies to determine the interaction of refugee children with other children and the problems encountered in preschool period are quite limited (Avc1, 2019; Mercan Uzun \& Tüm, 2016). Therefore, it is thought that this study will contribute to the literature by examining the interaction of Turkish children and refugee children in the classroom environment as observed by teachers.

\section{Method}

\subsection{Research Design}

This qualitative study is designed as a phenomenology study. Phenomenology design aims to investigate the phenomena we are familiar with but whose meaning is not fully understood (Yıldırım \& Şimşek, 2018). The phenomenology method is an appropriate tool to consider "refugee children's educational process" as mediated by pre-school teachers' opinions.

\subsection{Study group}

The study group consists of 15 preschool teachers working in the central districts (Ípekyolu, Edremit and Tusba) of Van province. The study group was determined by using criterion sampling method, as one of the purposeful sampling methods. In criterion sampling, certain criteria are established and those who meet these criteria are selected for the study group (Büyüköztürk et al., 2019). In this study, "the presence of refugee children in their class" was determined as a criterion for preschool teachers and those who met this criterion were included in the study group.

Concerning the personal characteristics of teachers in the study group; twelwe of the teachers are female and three of them are male. Four of the teachers have 1-5 years, nine have 6-10 years, two have 11 years and more professional experience.

\subsection{Data Collection Tool and Process}

The study uses a semi-structured interview form which was developed by the researchers. The form consists of three open-ended questions covering the interaction of refugee children with other children in the classroom environment, the prejudice or discriminatory behaviors of other children towards refugee children, and the solutions suggested by teachers regarding the education of refugee children. The draft form was sent to three experts working in Preschool Education, Turkish Education and Educational Sciences, and they were asked to examine the questions in terms of the language and content. Following their feedback, one of the four questions in the draft form was removed, and the other three questions were revised.

The interviews were held in the fall semester of the 2019-2020 academic year and conducted face to face with teachers by going to preschool institutions. Before the interviews, permission was obtained from the ethics committee of Van Yüzüncü Yıl University and an application permission was obtained from the Van National Education Directorate. The interviews were conducted on a voluntary basis and the participants were made to fill in the consent form. The interviews were conducted by the researchers by verbally directing the questions in the interview form to the participants and recorded with a tape recorder. Each interview lasted approximately 30 minutes. The sound recordings obtained were transcribed by the researchers. 


\subsection{Data Analysis}

Descriptive analysis technique, one of the qualitative data analysis techniques, was used in the analysis of the data. This technique establishes themes based on the research data, the data are then arranged and interpreted according to the themes determined (Yıldırım \& Şimşek, 2018).

Before the themes were determined, the researchers analyzed the data to establish the codes which were then finalized by looking at the harmony between the codes. The researchers looked at the common features of the codes and considered the research questions to create the themes. Finally, the data were processed under appropriate themes and interpreted by making the necessary descriptions.

In order to ensure external reliability, detailed explanations were made concerning the method and processes followed in the study. In order to ensure internal reliability, the data were seperately coded by the researchers based on the formula proposed by Miles and Huberman (1994), and then the consistency between the codings was examined. According to this formula (Reliability = Consensus / [consensus + disagreement]), the percentage of consistency between coders was calculated as $92 \%$ and therefore coding was found to be sufficiently reliable (Miles \& Huberman, 1994). Also, in this study, descriptions were constantly reviewed and data were enriched with direct quotations to ensure internal and external validity. As a final remark, the teachers were labeled as $\mathrm{Tx}$ in reference to the study ethical considerations.

\section{Results}

In line with the teachers' opinions obtained in this study; the data were examined under three themes that are "interaction of refugee children with other children", "prejudice/discriminatory behaviors against refugee children" and "suggestions for the education of refugee children". Research was grouped according to the themes, supported by teachers' opinions, as shown below.

\subsection{Refugee Children's Interaction with Other Children}

The question "How do you evaluate the interaction of children with refugee children in your classroom? Can you give an example of complete integration and acceptance in your classroom? Please explain by describing the example situations (events) you have encountered." was posed to the teachers. In the interviews with the teachers; it was revealed that two-thirds of the teachers $(n=10)$ stated that there was no complete integration environment in the classroom with refugee children. In this regard, T4 asserted that "There is no such thing as not accepting or discriminating, but because my student does not have a good command of Turkish, there is a problem in speaking and understanding with children." Similarly, T14 and T8 stated that respectively:

At first they did not accept it, of course they tried to talk to them, but they paused first because the child did not answer. Frankly, the refugee child went through a process of adaptation, even cried in the early stages and did not want to come to school. (T14)

The language of my child, who is in my class now, is very insufficient, so he knows very little Turkish. That's why we sometimes have trouble with the integration, which can cause the child to be excluded by other friends. They want to communicate, but at points where they disagree, other children retreat, so unfortunately we cannot describe about a complete integration environment. (T8)

As stated in the teachers' opinions above, most of the teachers stated that there was no complete integration especially due to the language problem. In other words, they stated that refugee children had difficulty in communicating with other children because they do not know Turkish very well, they were unable to integrate, and therefore there was a state of exclusion or nonacceptance. Two teachers, on the other hand, pointed out that refugee children sometimes have discipline problems because their family and cultural structure is different. T6 coded teacher's opinion regarding this situation is as presented below:

There are points where we differ in terms of family structure in our society and their family structure, and the methods of providing the discipline for their children. Especially when there is a holiday, I 
observe in refugee children not accepting the order in the school. In this respect, only this can be a problem."

On the other hand, one third of the teachers $(n=5)$ stated that there was no problem in the interaction of children in their class with refugee children, and there was a complete integration environment. For instance, T9 pointed out:

I can speak of an atmosphere of complete acceptance, they certainly did not separate him. Just how can I say my child has a nerve, has an offended behavior for the slightest thing. We have a bit of conflict because of him, but there is absolutely no exclusion apart from that.

In addition, T13 asserted that, "The children don't have any problems. In this sense, I think they get along very well. In fact, the refugee kid in my class is more leader and social than other students."

As stated in the teachers' opinions above, some teachers stated that there is complete integration in the classroom environment. It is seen that the teachers emphasized the most important reason for refugee children's not having any problems as expressing themselves and communicating.

\subsection{Prejudice/Discriminatory Behaviors Towards Refugee Children}

The question "Do you think other children have prejudices/discriminatory behaviors against refugee children during pre-school education?" was posed to the teachers. In the interviews with the teachers; almost all of the teachers $(n=12)$ stated that other children in the class did not exhibit prejudice or discriminatory behaviors against refugee children. For instance, T1 remarked that "No. On the contrary, they are trying to help, to include them in their games.". Another teacher, T13, stated that:

There is no discrimination or exclusion, so the other students did not even feel that it was different. If I take you to the classroom right now, if you observe, you wouldn't be able to understand which one is a refugee child.

As stated in the teachers' views above, the majority of teachers are aware of their children's ethnicity, language, culture, etc. Emphasizing that their age is too young to discriminate and that they regard everyone as children despite all differences, they stated that the children in the classroom do not exhibit prejudice or discrimination towards refugee children and even adopt them. On the other hand, three teachers stated that other children in the classroom exhibit prejudice, exclusion or discrimination towards refugee children. Striking views of T15 and T5 regarding this situation are presented below:

Yes I did. Considering the reasons for these exclusionary behaviors, the student's speaking style was different, he could not speak Turkish correctly and fluently. This could have an effect, or he was coming in occasionally wearing local clothes. Maybe it was effective too. In this case, the refugee child was a bit withdrawn, and when other children did not let him in, he was quietly playing in his corner. He was trying to find a different activity for himself. (T15)

I saw that my students had prejudices against the Syrian student last year. The child knew Turkish, but as I said, sometimes children can marginalize each other in terms of clothing, care can be important. They can be discriminatory because they do not pay attention to childcare. (T5)

As a final example in this regard, T10 stated that "We have Afghan students who act violently when they get angry, or refugee students who shout and push their friend because they can't express themselves."

As emphasized in teachers' views above, some teachers' stated that the students exhibit prejudice, exclusion or discrimination against refugee children due to the differences such as language, culture, dressing style, etc. Teachers stated that refugee children, especially when they are excluded because they cannot express themselves, often exhibit the behaviors of anger, violence and sometimes timidity. 


\subsection{Recommendations for the Education of Refugee Children}

The question "What are your suggestions for supporting positive interaction of refugee children with other children in preschool education and eliminating prejudices/discrimination? was posed to the teachers. In the interviews, almost all of the teachers $(n=14)$ suggested that language training should be given to refugee children. Approximately half of the teachers made suggestions such as providing orientation/adaptation programs to refugee children $(n=7)$, ensuring family participation $(n=6)$, and creating a positive/supportive classroom environment. For instance, T5 and T11 pointed out:

Children should be given language training before children register. Kindergarten students should be given an orientation training for a week when they start school, and it would be good to give such an education to refugee children. (T5)

We can bring them together with their friends in activities. Instead of excluding him because he does not know the language, it is necessary to include them in activities by stating that we understand him. Instead of keeping them separate, activities should be done to integrate them with the students. (T11)

Another teacher, T15 also asserted that, "These children have trouble in speaking. Therefore, games, songs, drama activities can be organized to integrate these children into the classroom.

As emphasized in the teachers' opinions above, teachers think that Turkish language education should be given to refugee children in order to solve the language problem. In addition, they stated that integration training should be given, family participation should be provided and activities should be carried out to integrate them with other students. Some teachers made suggestions such as training families of refugee children $(n=5)$, training teachers $(n=4)$, having assistant teachers who know their language $(n=3)$ and providing psychological support to refugee children $(n=1)$. For instance, T2 remarked that, "Teachers can be trained. Information can be provided on how to educate refugee children and how to integrate them into the classroom." Another teacher, T15 asserted that, "Special courses can be organized especially for language problems. Psychological support can also be provided, because many of them do not live in good conditions.". As a final example, T12 pointed out:

We cannot communicate with parents, so they are not very active in the education of the child. Parents can be trained, especially in terms of adaptation, because the children adapt after a certain period of time. But I don't think families adapt, because they are too quiet, they are timid, there is no communication effort. As an assistant teacher, it might be better if a teacher who knows them better and understands their language is also in the classroom.

\section{Discussion, Conclusion and Suggestions}

In this study, most of the teachers stated that there is no complete integration in the classroom environment with refugee children. However, as stated by Stewart and Shaffer (2015), education provides social networks and communication opportunities for refugee individuals to adapt to society. In addition, education is vital for refugees' integration into society (Mamei et al., 2019). In refugee children's education, "the integration of children" is the most preferred among three situations that are isolation, assimilation and integration. Mental health of children and adolescents can be protected with a healthy integration (Karaman \& Bulut, 2018). In this case, it is seen that education is one of the most important tools in the integration of refugee children into society, and the basis of this education process is preschool education. Based on the results of this study, it can be said that the interaction and integration of refugee children with other children in preschool education is not at the desired level, so necessary practices should be introduced to ensure this integration.

According to the teachers' opinions, it was concluded that refugee children had difficulty in communicating with other children because they do not know Turkish very well, they were not able to integrate and therefore were excluded or rejected by other children. This result supports similar study results in the literature. In line with the results of this study, many studies in the 
literature (İçduygu \& Şimşek, 2016; Kardeş \& Akman, 2018; Mestheneos \& Ioannidi, 2002; Kozikoğlu \& Aslan, 2018) determined that not speaking the Turkish language is an important obstacle. Similarly, in the studies by Mercan Uzun and Bütün (2016) and Avc1 (2019), it was stated that refugee children studying in preschool education institutions had difficulty in communicating with other children and teachers. Because of the fact that they did not speak Turkish, they remained outside of the group and they could not socialize. Therefore, it can be said that the most important obstacle in the interaction and integration of refugee children with other children is the language problem. The language problems they experience are an important obstacle to their communication with their social environment. In addition to cognitive, social and emotional problems, it causes individuals to understand the lesson later than their peers (Karaman \& Bulut, 2018). Considering that language is the most important tool in communication, this can be considered as an expected result. It is possible to say that refugee children not understanding what other children say or other children seing that refugee children cannot speak cause communication/interaction to break, refugee children to be isolated from the environment and prevent integration.

In this study, according to some teachers' opinions, it was determined that the way children were raised in the family and cultural differences in some cases cause discipline problems in refugee children. In parallel with the results of this study, Ager and Strang (2008) stated that the unfamiliarity of different cultural groups to the culture of the resident group is one of the important obstacles in adapting to the educational process. Similarly, Soylu et al. (2020) concluded that the lack of knowledge about students' cultural background is one of the main obstacles to education. The study conducted by Avc1 (2019) determined that refugee children studying in preschool education institutions have difficulty in adapting due to cultural differences. Every child carries his world to the classroom environment. The cultural characteristics of the child such as the family's upbringing style and habits are reflected in their behavior in the classroom environment. These are known as out of school factors affecting classroom management (Aydın, 2019). Therefore, it can be said that the different cultural characteristics of refugee children from existing/established cultural values creates an obstacle in classroom management by making student-student and student-teacher interaction difficult.

In this study, the majority of the teachers stated that the students are too young to discriminate because of refugee children's race, language, culture, etc., they see everyone as children despite all differences, and it was concluded that the children do not exhibit prejudice or discrimination against refugee children unless there is a communication problem arising from language, they cooperate and share. However, when the literature is examined, it is seen that children have prejudices against children whom they define as strangers who are not from their own group (Aboud et al., 2012; Burkholder et al.,2019; Raabe \& Beelmann, 2011). Similarly, in the study of Mercan Uzun \& Bütün (2016), preschool teachers stated that children and parents had negative attitudes towards refugee children. Contrary to the studies in the literature, in this study, it can be stated that, according to the opinions of most teachers, the fact that other children do not exhibit prejudice or discrimination against refugee children is related to the informative, egalitarian and supportive attitude of teachers or the way children are raised in the family. This situation can be considered as a positive result in terms of the formation of a multicultural and inclusive education environment and the effective integration of refugee children into education. On the other hand, there have been a few teachers who stated that children exhibit prejudice, exclusion or discrimination against refugee children. Similarly, Spears Brown and Bigler (2005) concluded in their study that refugee children are more excluded due to the different cultural groups they have. It can be said that factors such as children's perception of refugee children as different, having difficulties in communicating, and parents' negative attitudes towards refugee children contribute to this situation.

In this study, it was concluded that almost all of the teachers emphasized that language education should be given to refugee children. In addition, teachers made suggestions such as 
providing orientation/adaptation training to refugee children, ensuring family participation and creating a positive/supportive classroom environment. These research results coincide with the results of similar studies in the literature. In their study, Yanik Özger and Akansel (2019) concluded that the close relationship established by Syrian families with school and their positive attitude towards language learning facilitate the adaptation process of children to school. Therefore, supporting families' language acquisition and increasing their communication with the school is important in terms of children's adaptation and academic success. For the adaptation and education of refugee children, it should be a program that will integrate different cultural groups into the Turkish education system and be sensitive to their needs. However, Aydin et al. (2019) concluded in their research that the Turkish education system is inadequate in education of multiculturalism and diversity. In their study, Tropp and Prenovost (2008) concluded that the interaction between different cultural groups positively affects children's attitudes towards individuals from different cultures and causes children to have positive feelings towards differences. However, teachers should teach children to accept and respect differences, and should be supported by programs and resources for the education of themselves, families and children (D'angelo \& Dixey, 2001).

In summary, this study revealed that although there is no full integration environment in classrooms, there is no prejudice or discriminatary behaviors towards refugee children, and Turkish children cooperate and share with refugee children. It was concluded that not being able to speak the Turkish language is an important obstacle in the education and adaptation of refugee children, and the way children are brought up in the family and cultural differences sometimes cause disciplinary problems in refugee children. Based on the results of this study and the suggestions of preschool teachers, the following suggestions are presented for the education of refugee children in preschool education and new researches.

1. To provide Turkish language education to refugee children and their families in order to ensure the integration of refugee children.

2. To develop and implement adaptation training programs for refugee children to adapt effectively to the Turkish Education System, cultural characteristics and school environment.

3. To carry out family participation activities for the families of refugee children to participate in the education process at school.

4. To create a positive/supportive classroom environment for refugee children, including multicultural and inclusive education practices that will ensure the reflection of children's cultural differences in the classroom environment.

This study is limited to interviews with 15 preschool teachers. By using measurement tools such as survey, scale, etc., larger and different samples can be studied. More in-depth studies can be conducted with data collection tools such as observation, diary etc.

\section{References}

Aboud, F. E., \& Amato, M. (2001). Developmental and socialization influences on intergroup bias. Blackwell handbook of social psychology: Intergroup processes. Blackwell.

Aboud, F. E., \& Fenwick, V. (1999). Exploring and evaluating school based interventions to reduce prejudice. Journal of Social Issues, 55(4), 767-785.

Aboud, F. E., Tredoux, C., Tropp, L. R., Brown, C. S., Niens, U., \& Noor, N. M. (2012). Interventions to reduce prejudice and enhance inclusion and respect for ethnic differences in early childhood: A systematic review. Developmental review, 32(4), 307-336.

Ager, A., \& Strang, A. (2008). Understanding integration: A conceptual framework. Journal of refugee studies, 21(2), 166-191.

Allport, G. W. (1979). The nature of prejudice. Addison-Wesley.

Araujo, L., \& Strasser, J. (2003). Confronting prejudice in the early childhood classroom. Kappa Delta Pi Record, 39(4), 178-182. https:/ / doi.org/10.1080/00228958.2003.10516402 
Avcl, F. (2019). Teachers' opinions on the problems faced by the refugee students in preschool education institutions. Language Teaching and Educational Research,2(1), 57-80. https://doi.org/10.35207/later.537817

Aydın, A. (2019). Sinıf yönetimi [Classroom management]. Pegem.

Aydın, H., Gündoğdu, M., \& Akgül, A. (2019). Integration of Syrian refugees in Turkey: Understanding the educators' perception. Journal of International Migration and Integration, 20(4), 1029-1040. https:/ / doi.org/10.1007/s12134-018-0638-1

Banks, J. A. (1991). Multicultural education: For freedom's sake. Educational Leadership, 49(4), 32-36.

Başar, M., Akan, D., \& Çiftçi, M. (2018). Learning-teaching process 1ssues in classrooms with refugee students. Kastamonu Education Journal, 26(5), 1571-1578. https://doi.org/ 10.24106/kefdergi.427432

Bigler, R. S., \& Liben, L. S. (1993). A cognitive-developmental approach to racial stereotyping and reconstructive memory in Euro-American children. Child development, 64(5), 1507-1518. https:// doi.org/10.2307/1131549

Bigler, R. S., \& Liben, L. S. (2007). Developmental intergroup theory: Explaining and reducing children's social stereotyping and prejudice. Current Directions in Psychological Science, 16(3), 162166. https:// doi.org/10.1111\%2Fj.1467-8721.2007.00496.x

Boutte, G. S. (2008). Beyond the illusion of diversity: How early childhood teachers can promote social justice. The Social Studies, 99(4), 165-173. https:/ / doi.org/10.3200/TSSS.99.4.165-173

Burkholder A.R., D'Esterre A.P., \& Killen M. (2019). Intergroup relationships, context, and prejudice in childhood. In Fitzgerald H., Johnson D., Qin D., Villarruel F., Norder J. (Eds.), Handbook of children and prejudice (pp. 223-238). Springer.

Büyüköztürk, Ş., Kılıç-Çakmak, E., Akgün, Ö.E., Karadeniz, Ş., \& Demirel, F. (2019). Bilimsel araştırma yöntemleri[Scientific research methods]. Pegem.

Cameron, J. A., Alvarez, J. M., Ruble, D. N., \& Fuligni, A. J. (2001). Children's lay theories about ingroups and outgroups: Reconceptualizing research on prejudice. Personality and Social Psychology Review, 5(2), 118-128. https:/ / doi.org/10.1207\%2FS15327957PSPR0502_3

Carter, C., \& Rice, C. L. (1997). Acquisition and manifestation of prejudice in children. Journal of Multicultural Counseling and Development, 25(3), 185-194. https://doi.org/10.1002/j.21611912.1997.tb00328.x

Clark, K. B., \& Clark, M. P. (1958). Racial identification and preference in Negro children. In E. E. Maccoby, T. M. Newcomb, \& E. L. Hartley (Eds.), Readings in social Psychology (pp. 169-179). Holt, Rinehart, \& Winston.

Crary, E. (1992). Talking about differences children notice. In B. Neugebauer (Ed.), Alike and different: Exploring our humanity with young children (pp. 11-15). Exchange Press.

D'angelo, A. M., \& Dixey, B. P. (2001). Using multicultural resources for teachers to combat racial prejudice in the classroom. Early Childhood Education Journal, 29(2), 83-87. https:/ / doi.org/10.1023/A:1012516727187

Devine, P. G. (1989). Stereotypes and prejudice: Their automatic andcontrolled components. Journal of Personality and Social Psychology, 56, 5-18. https://psycnet.apa.org/doi/10.1037/00223514.56.1.5

Duckitt, J., Wall, C., \& Pokroy, B. (1999). Color bias and racial preference in White South African preschool children. Journal of Genetic Psychology, 160, 143-154. https://doi.org/10.1080/ 00221329909595388

Erdem, C. (2017). Instructional problems experienced by primary school teachers who have refugee students in their classes and their solutions for problems. MEAD, 1(1), 26-42.

Güngör, F., \& Şenel, E. A. (2018). Teachers and students views in problems of the foreign primary school students in education process encountered. Anadolu University Journal of Educational Sciences, 8(2), 124-173.

Healey, J. F., Stepnick, A., \& O'Brien, E. (2018). Race, ethnicity, gender, and class: The sociology of group conflict and change. Sage. 
İçduygu, A., \& Şimşek, D. (2016). Syrian refugees in Turkey: Towards integration policies. Turkish Policy Quarterly, 15(3), 59-69.

Karaman, H. B., \& Bulut, S. (2018). An investigation of educational obstacles, psychological problems and solution proposals of migrant children and adolescents. Journal of Social Policy Studies, 40(2), 393-412.

Kardeş S. (2018). Adaptation of the program for psychosocial development of refugee children (Unpublished Doctoral Thesis). Educational Science Enstitute, Hacettepe University, Ankara.

Kardeş, S., \& Akman, B. (2018). Teachers' views on the education of Syrian refugees. Elementary Education Online, 17(3), 1224-1237.

Kelly, D. J., Quinn, P. C., Slater, A. M., Lee, K., Gibson, A., Smith, M., ... \& Pascalis, O. (2005). Three-month-olds, but not newborns, prefer own-race faces. Developmental Science, 8(6), 31-36.

Killen, M., Mulvey, K. L., \& Hitti, A. (2013). Social exclusion in childhood: A developmental intergroup perspective. Child Development, 84, 772-790. https://psycnet.apa.org/doi/ 10.1111/cdev.12012

Killen, M., \& Rutland, A. (2011). Children and social exclusion: Morality, prejudice and groupidentity. Wiley-Blackwell.

Kozikoğlu, I., \& Aslan, M. (2018). Socio-cultural, psychological and academic problems of undergraduate Syrian students in Turkey. Issues in Educational Research, 28(3), 701-719.

Mamei M., Cilasun S.M., Lippi M., Pancotto F., \& Tümen S. (2019). Improve education opportunities for better integration of Syrian refugees in Turkey. In Salah A., Pentland A., Lepri B., Letouzé E. (Eds.) Guide to Mobile Data Analytics in Refugee Scenarios (pp. 381-402). Springer.

McGlothlin, H., \& Killen, M. (2006). Intergroup attitudes of European American children attending ethnically homogeneous schools. Child development, 77(5), 1375-1386. https://doi.org/10.1111 /j.1467-8624.2006.00941.x

Mercan Uzun, E. M., \& Bütün, E. (2016). Okul öncesi eğitim kurumlarındaki Suriyeli sığınmacı çocukların karşılaştıkları sorunlar hakkında öğretmen görüşleri[Teachers' views regarding the problems encountered by Syrian refugee children in preschool education institutions]. International Journal of Early Childhood Education Studies, 1(1), 72-83.

Mestheneos, E., \& Ioannidi, E. (2002). Obstacles to refugee integration in the European Union member states. Journal of Refugee Studies, 15(3), 304-320.

Miles, M. B., \& Huberman, A. M. (1994). Qualitative data analysis: An expanded sourcebook. Sage.

Öztürk, F. Z. (2018). Evaluation of educational service provided for refugee students according to social studies teachers' opinions. Anadolu Journal of Educational Sciences International, 8(1), 52-79.

Powlishta, K. K., Serbin, L. A., Doyle, A.-B., \& White, D. R. (1994). Gender, ethnic, and body type biases: The generality of prejudice in childhood. Developmental Psychology, 30(4), 526-536. https://doi.org/10.1037/0012-1649.30.4.526

Raabe, T., \& Beelmann, A. (2011). Development of ethnic, racial, and national prejudice in childhood and adolescence: a multinational meta-analysis of age differences. Child Development, 82(6), 1715-1737. https:/ / doi.org/10.1111/j.1467-8624.2011.01668.x

Rubin, K. H., Bukowski,W., \& Parker, J. G. (2006). Peer interactions, relationships and groups. In W. Damon, R. M. Lerner, \& N. Eisenberg (Eds.), Handbook of Child Psychology. Social, emotional, and personality development (pp. 571-645). Wiley.

Rutland, A., \& Killen, M. (2015). A developmental science approach to reducing prejudice and social exclusion: Intergroup processes, social-cognitive development, and moral reasoning. Social Issues and Policy Review, 9(1), 121-154. https:/ / doi.org/10.1111/sipr.12012

Soylu, A., Kaysıl1, A., \& Sever, M. (2020). Refugee children and adaptation to school: An analysis through cultural responsivities of the teachers. Education and Science, 45(201), 313-334.

Spears Brown, C., \& Bigler, R. S. (2005). Children's perceptions of discrimination: a developmental model. Child Development, 76(3), 533-553. https:// doi.org/10.1111/j.1467-8624.2005.00862.x 
Stewart, E., \& Shaffer, M. (2015). Moving on? Dispersal policy, onward migration and integration of refugees in the UK, Economic, social and research council. http://www.migrationscotland.org.uk/ uploads/usercontributed/Moving_OnFinal_Report 2015.pdf

Şimşir, Z., \& Dilmaç, B. (2018). Problems teachers' face and solution proposals in the schools where the foreign students are educated. Elementary Education Online, 17(3), 1719- 1737.

Tajfel, H., Turner, J. C., Austin, W. G., \& Worchel, S. (1979). An integrative theory of intergroup conflict. http://www.ark143.org/wordpress2/wp-content/uploads/2013/05/Tajfel-Turner1979-An-Integrative-Theory-of-Intergroup-Conflict.pdf

Tan, G. (2001). "I want my teachers to like me": Multiculturalism and school dropout rates among Mexican Americans. Equity and Excellence in Education, 34(2), 35-42. https://doi.org/10.1080/ 1066568010340206

Tosun, A., Yorulmaz, A., Tekin, İ., \& Y1ld1z, K. (2018). Problems and expectations of refugee students about education and religious education: Case of Eskişehir. Eskisehir Osmangazi University Journal of Social Sciences, 19(1), 107-133.

Tropp, L. R., \& Prenovost, M. A. (2008). The role of intergroup contact in predicting children's interethnic attitudes: Evidence from meta-analytic and field studies. In S. R. Levy \& M. Killen (Eds.), Intergroup attitudes and relations in childhood through adulthood (pp. 236-248). Oxford University Press.

Williams, D., \& Nguyen, V. (2018). Beyond the golden rule: a parent's guide to preventing and responding to prejudice. SPLC. http://www.learningforjustice.org/sites/default/files/general/ beyond_golden_rule.pdf

Yanık Özger, B. ve Akansel, A. (2019An ethnographic case study on Syrian children and their families in preschool class: we are also in this class! Journal of Qualitative Research in Education, 7(3), 942-966.

Yıldırım, A., \& Şimşek, H. (2018). Sosyal bilimlerde nitel araştırma yöntemleri [Qualitative research methods in the social sciences]. Ankara: Seçkin Yayıncılık. 